\title{
Diagnosis and dental treatment of rickets: A case report
}

\author{
Joongi Hong', Sung-Joon Kim ${ }^{1,2}$, and Se Hoon Kahm ${ }^{1,2 *}$ \\ ${ }^{1}$ School of Medicine, Jeju National University, Jeju 63243, Republic of Korea \\ ${ }^{2}$ Department of Dentistry, Jeju National University Hospital, Jeju 63241, Republic of Korea
}

(Received Dec 11, 2017; Revised version received [1] Mar 8, 2018 [2] Mar 15, 2018; Accepted Apr 17, 2018)

\begin{abstract}
Rickets is a disease caused by vitamin D deficiency. The lack of vitamin D and other minerals can cause weak or soft bones and dysplasia of the teeth. Rickets is identified by clinical symptoms such as bowlegs or knock-knees, and can be confirmed with laboratory tests. Dental findings include enlarged chambers and high pulp horns that extend into the cusp tips of both the primary and the permanent dentition. Other oral manifestations include multiple spontaneous abscesses in a caries-free dentition. Yet another problem is enamel hypoplasia. We reported the clinical features of rickets and the dental treatment of an 11-year-old boy with hypophosphatemic rickets, which was referred to the department of pediatrics in Jeju National University Hospital for dental care. and other children's medical records.
\end{abstract}

KEY WORDS: Enamel hypoplasia, Hypophosphatemic rickets, Rickets

\section{서 론}

구루병은 비타민D 결핍으로 인해 골조직의 연화 및 치아 조직의 형성부전을 가져오는 질환으로 유아나 어린이에서 호발하는 질환이다. 구루병은 드물게 발생하는 질환으로 알려져 있지만, 2000년대 이후로 발생률은 급격하게 증가 하고 있는 추세다. 미국의 미네소타 주에서는 2002년에 비 해 2008년 비타민 D결핍증 혹은 구루병이 10배 이상 증가 하기도 하였다[1]. 이러한 구루병의 증가 양상은 한국 또한 크게 다르지 않으며, 한국이 심한 비타민D 부족·결핍 국가 중 하나라는 점에서 이를 새로운 문제를 생각해 볼 수 있 다[2]. 이러한 점을 고려해 봤을 때, 우리는 구루병을 문헌 속의 옛날 질병으로만 생각할 것이 아니라 이에 대한 지식 을 갖추고 치료법에 대해서도 숙지할 필요가 있겠다.

알려진 바와 같이, 구루병은 비타민 $\mathrm{D}$, 인, 칼슘 대사 장애 나 부족으로 인해 소아의 성장판 유합 이전에 빼의 석회화 (calcification)나 무기질화(mineralization)에 결함이 생기는 질 병이다[3,4]. 따라서 대부분의 성장판에서 뼈의 기형이 나타 나게 된다. 손목, 팔꿈치, 무릎은 두꺼워지고 장골은 짧아지

*Corresponding author: Se Hoon Kahm

Department of Dentistry, Jeju National University Hospital, Aran 13-gil 15, Jeju-si, Jeju-do 63241, Republic of Korea

Tel.: +82-64-717-1331, Fax: +82-64-717-1846

E-mail: SeHoon.Kahm@gmail.com
고, 길이 성장의 감소와 각도의 기형이 나타날 수 있다. 골격 의 변형뿐만 아니라 근육 및 면역 계통에도 이상이 생길 수 있다. 근긴장도가 떨어지거나, 잘 보채고, 앉고 서고 걷는 발 달 과정이 지연되기도 한다. 일반적으로 알려진 구루병의 골 격 기형과 관련된 특성이 많은 관계로 치과의사들은 구루병 에 크게 관심을 두지 않지만 구루병은 구강 내에도 다양한 문제를 야기할 수 있다. 구루병의 주요한 구강 내 특징으로 외상이나 치아 우식증 없이 자발적으로 생기는 치은 농양, 치주 농양이 있다[5]. 또한 가장 흔한 치과적 문제로 치아 우 식증과 일차 혹은 영구치 치열의 맹출 지연이 발견된다[6]. 이 외에도 법랑질 저형성증, 치은염, 확대된 치수강과 치수 각, 우상치(taurodontism) 등이 나타날 수 있다[7-9].

따라서 치과의사들도 구루병에 대해 인지하고 있어야 하 며, 이의 구강 내 증상에 알맞게 대처할 수 있어야 한다. 또 한, 이러한 구강 내 증상 및 일반적인 증상을 통해 구루병 의 조기진단에도 도움을 줄 수도 있을 것이다. 우리는 본 증례를 통하여 구루병에 대한 전반적인 이해와 그에 따른 구강 내 증상을 알고, 이에 대한 적절한 치료법을 알아보고, 구루병의 진단과 치료에 도움이 되고자 한다.

\section{증례보고}

본 연구는 제주대학교병원 임상의학연구소 연구윤리 심 의(JEJUNUH 2017-02-002)를 거쳐서 연구에 필요한 전자 
의무기록 및 영상자료를 통하여 연구를 진행하였다.

11세 남아가 제주대학교병원 소아청소년과에서 치과적 정기 관리를 위하여 원내 의뢰되었다. 환아는 만2세경 해 외에서 아이가 일어서거나 걷는 것을 월령에 비하여 잘못 하는 것을 주소로 거주지 종합병원으로 내원하여 임상의 학적, 혈액학적, 영상의학적 검사를 시행한 후에 저인산혈 증 구루병(hypophosphatemic rickets)으로 진단받고, 이에 대한 치료를 시작하였으며, 구루병을 제외한 다른 전신병 력을 가지고 있지는 않았다. 이후 3 개월마다 혈액검사와 소변검사를 받으며 약물 치료를 이어 오고 있었다. 국내로 이주한 후, 2015년 3월 14일 제주대학교병원 소아청소년 과로 내원하여 전반적인 검사를 재시행하고, 현재 환자의 비타민 D 결핍 상태 및 구루병의 치료를 위한 정기진료

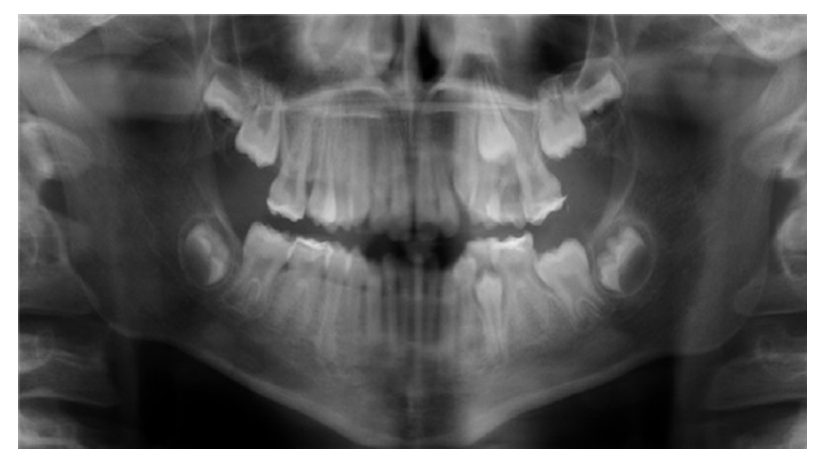

Fig. 1. Panoramic view of a patient with rickets, taurodontism can be seen in molars.

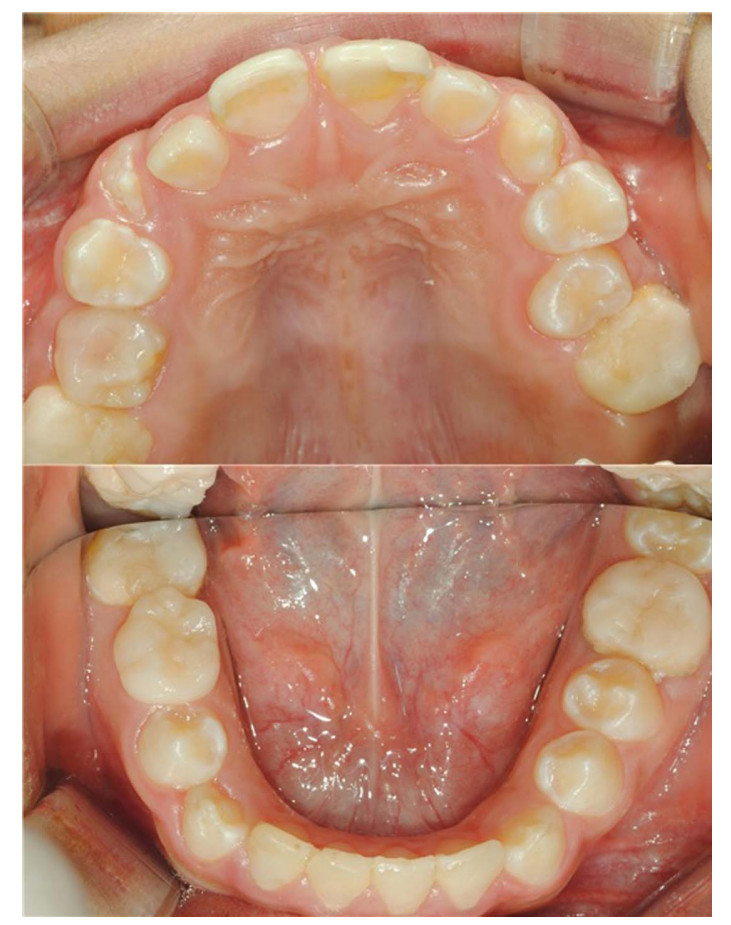

Fig. 2. Intraoral image of a patient showing enamel hypoplasia and composite resin restorations can be seen in various teeth.
및 약물치료를 시행해 오고 있었고, 약물의 반응에 따라서 투약방법을 변경, 조정하기도 하였다.

이후 3 개월마다 경과 관찰 및 검사, 투약을 반복하여 관 리 중에 있었고, 보호자의 요청으로 치과검진 및 치료를 위하여 2016년 2월 22일 제주대학교병원 치과진료부로 의 뢰되었다. 환아는 치과 내원 당시 해외에서 법랑질 형성 부전 부위의 복합레진 수복을 받은 상태였으며, 영구치의 결손이나 치은, 치주의 염증은 발견되지 않았다. 환아의 영 상의학적인 기초 검사를 위해 파노라마방사선 사진(Fig. 1) 을 촬영하였으며, 맹출 중인 견치에서는 법랑질 형성부전 으로 인한 치아 외형의 결함(defect)을 확인할 수 있었다 (Fig. 1 and 2). 내원 당일에는 치아의 맹출이 충분하지 않 았으므로, 불소도포를 하고 경과를 관찰하기로 하였다.

이후 2017년 1월 25일 내원시에는 법랑질 형성 부전증 을 보이는 \#13, \#23 치아에 대한 복합레진 수복을 시행하 여, 환아의 치아의 정상적인 외형을 회복하였다. 이후에도 영구치 맹출 확인과 치아우식증, 치은염의 관리를 위하여 소아청소년과와 협진하여 지속적인 경과를 관찰중이다.

\section{교 찰}

구루병의 종류는 여러 가지 기준에 의해 분류할 수 있

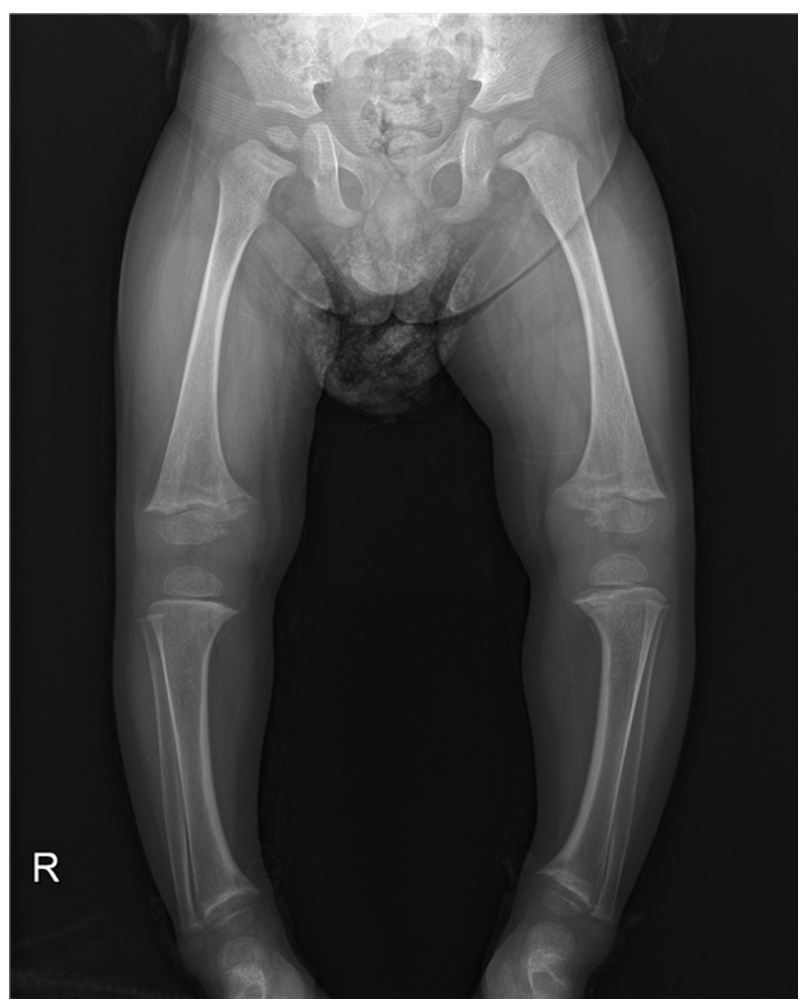

Fig. 3. A radiograph showing a characteristic genu varum of a typical rickets's infant. 
다. 일차적으로 부족한 무기질이 칼슘인지 인산인지 혹은 부족한 것이 알칼리성 인산분해효소 인지에 따라 분류할 수도 있고, 영양 결핍성과 비영양 결핍성으로 분류하기도 한다. 비영양 결핍성 구루병의 경우에는 약 $90 \%$ 가 신부전 이나 신세뇨관 이상같은 신장의 문제이며, $5 \sim 10 \%$ 정도가 유전성 저인산혈증 구루병이고, 비타민 $\mathrm{D}$ 의존성 구루병 은 $5 \%$ 이내로 알려져 있다[3].

이러한 구루병으로 인해 나타나는 증상은 원인과 무관 하게 비슷한 양상으로 나타난다. 우선 모든 성장판에서 뼈 의 기형이 나타난다. 손목, 팔꿈치, 무릎은 두꺼워지고 장 골은 짧아진다. 또한 장골에서 성장판 모양의 변화로 길이 성장의 감소와 각도의 기형이 나타난다. 이로 인해 내반슬 (genu varum)(Fig. 3)이나 외반슬(genu valgum), 혹은 내반 고(coxa vara)가 생긴다. 골격의 변형 외에도 근육 및 면역 계통에도 이상이 생긴다. 근긴장도가 떨어지거나, 잘 보채 고, 앉고 서고 걷는 발달 과정이 지연되기도 한다. 저칼슘 혈증과 관련된 근육 경축, 무호흡 발작, 경련 등의 병력이 있거나, 심근병증(cardiomyopathy), 호흡기계 및 위장관의 감염증을 동반하기도 한다[3]. 간혹 두개골의 발달 이상으 로 macrocephaly를 나타내기도 한다(Fig. 4). 뿐만 아니라, 다양한 치과적인 합병증을 나타내기도 한다. 주요한 구강 내 증상으로 외상이나 치아 우식증 없이 자발적으로 생기 는 치은 농양, 치주 농양이 있다[5]. 또한, 치아 우식증과 일차 혹은 영구치 치열의 맹출 지연이 나타나기도 한다 [6]. 이 외에도 법랑질 저형성증, 치은염, 확대된 치수강과 치수각, 우상치 등이 나타날 수 있다[7-9](Fig. 1).

본 증례의 환자는 저인산혈증 구루병(Hypophosphatemic rickets)으로 인 부족으로 인한 구루병에 속한다. 대부분의

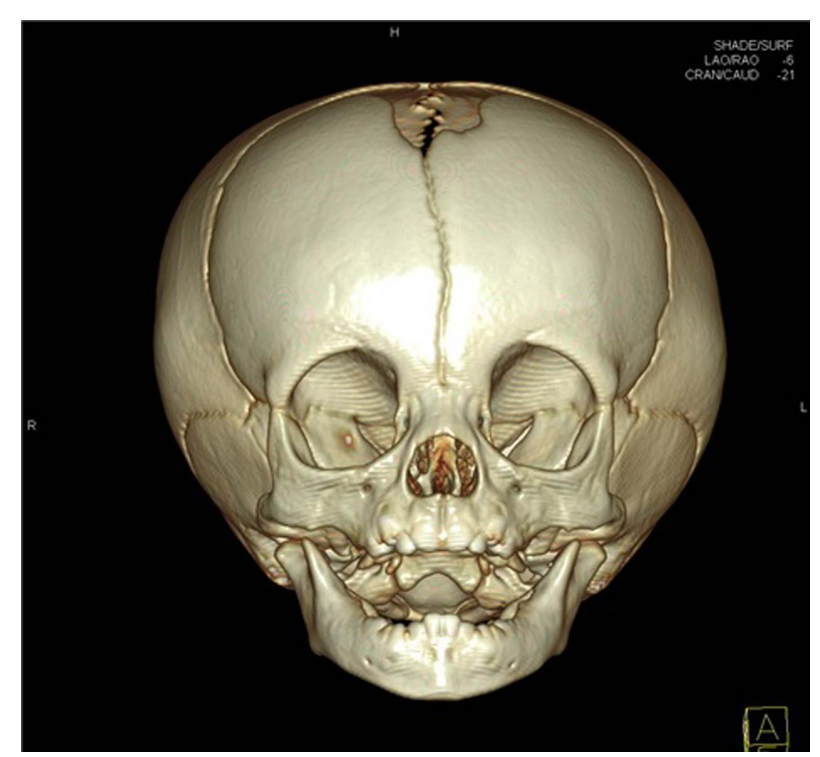

Fig. 4. Three-dimensional image of the skull of a child showing macrocephaly.
Hypophosphatemic rickets은 유전적으로 발현하는 질환이 다. 유전성 저인산혈증 구루병(hereditary hypophosphatemic rickets)은 유전자 이상으로 인해 인의 요 배출이 증가하여 저인산혈증이 유발되는 질환군이다. 여기에는 네 종류가 알려져 있다. 성염색체 우성(X-linked dominant) 유전 양상 을 보이는 X-linked hypophosphatemia가 가장 흔하며, 이 외에 상염색체 우성 저인산혈증 구루병(autosomal dominant hypophosphatemic rickets), 상염색체 열성 저인산혈증 구루병 (autosomal recessive hypophosphatemic rickets) 및 고칼슘뇨 동 반 유전성 저인산혈증 구루병(hereditary hypophosphatemic rickets with hypercalciuria)이 있다. X-linked hypophosphatemia, 상염색체 우성 저인산혈증 구루병, 상염색체 열성 저인산 혈증 구루병은 모두 섬유모세포 성장인자23(fibroblast growth factor 23, FGF23)의 유전적 문제로 인한 활성 증 가와 불활성화 억제에 의해 인산 배출이 증가하여 발생한다 . FGF23의 주된 기능은 인의 요 배출이다. 고칼슘뇨 동반 유 전성 저인산혈증 구루병에서는 $2 \mathrm{c}$ 형 나트륨-인산 공동운반 체(sodium-phosphate cotransporters)인 NaPi- $\Pi \mathrm{c}$ (SLC34A3)를 인코딩하는 유전자 돌연변이에 의해 신장에서의 인산 재 흡수가 감소한다[3].

저인산혈증 구루병의 임상 양상은 영양 결핍성 구루병 의 발생연령인 3-18개월 보다는 조금 늦은 나이인 1-2세 사이에 처음 나타나는 경우가 많다. 주 증상은 보행 발달 지연과 하지 각 변형이며, 영양 결핍성 구루병에서는 보이 는 자극에 대한 과민함이나 둔함은 경미한 경우가 많다. 치아에는 법랑질 저형성은 없으나, 상아질의 결손을 보이 며, 치아 농양이 발생하기도 한다[3]. 임상적으로 건전한 치아에 농양이 호발하는 이유는 심한 저인산혈증으로 인 해 조직학적으로 심부 상아질에 저석회화된 관간상아질 (intertubular dentin)이 많이 생성되기 때문이다. 이는 상아 모세포(odontoblast)의 기능이 정상이라 할지라도 저인산 혈증으로 인해 상아질의 석회화가 불충분하여 관간상아질 의 부위에서 저석회화되고 이형성된 상아질이 관찰되는 것이다. 이러한 불완전 석회화된 상아질은 수산화인회석 결절(hydroxyapatite nodule)의 형태로 존재하고 미생물의 서식처로 작용하여 근관치료시 기계적 세척작용을 방해하 는 요소가 되기도 한다. 또한, 구간 상아질(interglobular dentin)의 증가, 치수의 세포 성분의 감소 및 교원질 성분 의 증가 등의 소견이 나타나는데, 치수의 섬유성분의 증가는 상아모세포가 차지하는 부분과 재생성 상아질(reparative dentin)의 형성을 감소시켜 치수감염에 저항할 수 있는 능 력을 감소시키게 되고, 이것 또한 농양과 농루가 호발하는 이유가 된다. 또 다른 이유로는 조직학적으로 치수각이 법 랑상아경계 혹은 교두정까지 연장되어 미생물과 다른 유 해물질들이 치수로 교통하게 되는 교통로를 제공하기 때 문에 법랑질이나 상아질의 미세파절을 통한 미생물 침투 


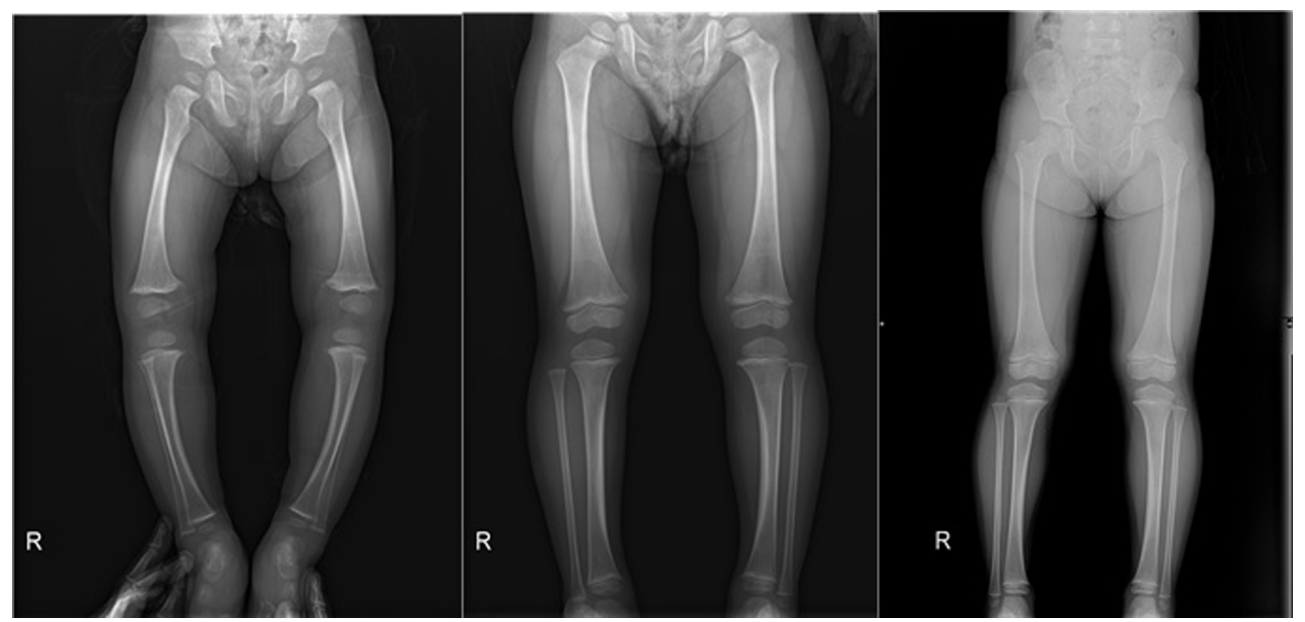

Fig. 5. Radiographs of patients normally growing with treatment of medication.

가 쉽게 일어날 수 있게 된다. 대개 농양이 처음 나타나는 나 이가 어릴수록 치과적 문제가 더 심각하다고 알려져 있다 [10-12]. 약물요법을 통하여 1.25-Dihydroxy-cholecalciferol 형 태의 비타민 $\mathrm{D}$ 를 보통 용량보다 적게 하여 인산염과 함께 혼 합 투여하는 것이 추천되며, 통상적으로 조기에 치료를 시작 하면 정상적인 발육을(Fig. 5) 기대할 수 있다고 한다[13].

본 증례의 환아는 2 세경 잘 일어서거나 걷지 못하는 것 을 주호소 증상으로 처음 병원을 방문하여 hypophosphatemic rickets를 진단받았다. 소아청소년과 외래 진료를 통해 정 기적으로 약물 치료를 진행하던 중 보호자의 요청으로 치 과로 방문하였다. 맹출중인 치아의 법랑질 저형성증이 관 찰되었고, 영구치 전치에서 기존 복합레진 수복이 관찰되 었었다. 또한 상악 견치 맹출중, 법랑질의 형성 부전 보여 복합레진 수복으로 치료하였다. 환아는 만2세경 구루병으 로 진단 받은 후에 이에 대하여 지속적인 약물 치료를 받 아온 결과, 장골의 성장과 형태에는 이상이 발견되지 않았 고, 치과적인 문제에서도 심각하지 않은 법랑질 형성부전 증만이 관찰되었다. 향후 지속적인 정기검진과 예방치료 를 통하여 정상적인 치아맹출과 발달을 유도할 수 있을 것 으로 여겨지며, 성인이 된 후에는 법랑질 형성부전의 복합 레진 충전 부위에 대한 재수복시술 혹은 치과보철치료가 필요할 수 있다. 이러한 관리가 지속된다면 환아는 큰 불 편감 없이 심미성과 기능성을 만족할 수 있는 구강기능을 유지할 수 있을 것이다. 국내의 기존 연구들에서도 특징적 소견으로 다수의 자발적 치근단 농양 및 농루, 치수각의 현저한 신장, 치아 맹출지연이 보고되었고, 치근단 농양 및 농루를 예방하기 위해 적극적인 예방치료가 필요하다 고 하였다[14,15]. 본 증례에서도 정기적인 치과검진과 예 방치료로 이에 맞추어 지속적인 환아의 구강 관리를 시행 해가고 있으며, 조기에 발견되어 약물치료를 진행한 경우 에는 사지의 변형 없는 장골의 성장과 발달을 관찰할 수
있었다.

하지만, 구루병 환자의 치과적 관리가 지속적으로 필요한 이유는 앞서 살펴본 바와 같이 이유를 알지 못하는 치은, 치 주 농양이 발생하거나, 확장된 치수로 인한 치수염의 발병으 로 인한 근관치료의 필요 등이 발생 할 수 있고, 약물치료를 하였더라도 치아의 석회화 문제를 개선할 수 없기 때문에, 이에 대하여 주기적인 관찰 및 적절한 치과 치료를 통하여 비정상적 치아발육과 상아질 형성을 관리하는 것이 필수적 이다. 따라서 치아의 발달문제로 약화된 치질에 대한 적절한 보호-예방적 불소도포 치료, 수복치료-와 구루병에 대한 의 학적 치료-약물치료와 정형외과적 처치-가 필요하다. 치과를 내원하는 영유아나 소아에서 내반슬 등의 장골의 기형 같은 사지의 외형적인 문제나 다발성 치아 우식증, 원인이 불명확 한 치은, 치주 농양, 법랑질 저형성, 치아 맹출 지연 등이 나 타난다면 구루병에 대해서 의심해 볼 필요가 있으며, 이를 감별진단 하여야 한다. 만약 소아청소년과나 정형외과 등의 협진으로 구루병으로 확진될 시에는 소아청소년과 전문의와 의 협진을 통한 약물치료와 정형외과 전문의와의 협진을 통 한 장골에 대한 평가 및 처치 그리고 주기적인 치과 검진과 치료가 필요할 것이다.

\section{감사의 글}

This work was supported by a research grant from Jeju National University Hospital in 2015.

\section{Conflict of Interest}

The authors declare that they have no competing interests. 


\section{ORCID}

$\begin{array}{ll}\text { Joongi Hong } & 0000-0001-7290-5034 \\ \text { Sung-Joon Kim } & 0000-0003-0603-4036 \\ \text { Se Hoon Kahm } & 0000-0001-6945-8480\end{array}$

\section{References}

1. Thacher TD, Fischer PR, Tebben PJ, Singh RJ, Cha SS, Maxson JA, Yawn BP. Increasing incidence of nutritional rickets: a population-based study in Olmsted County, Minnesota. Mayo Clin Proc 2013;88:176-183. doi: 10.1016/j.mayocp.2012.10.018.

2. Lee A, Kim SH, Nam CM, Kim YJ, Joo SH, Lee KR. Prevalence of vitamin D deficiency and insufficiency in Korean children and adolescents and associated factors. Lab Med Online 2016;6:70-78. doi: 10.3343/lmo.2016. 6.2.70.

3. The Korean orthopaedics association. Orthopaedics 7 th ed. Korea; 2013. p. 269-280.

4. Weinstein SL, Flynn JM. Lovell and Winter's pediatric orthopaedics 7 th ed. Lippincott Williams \& Wilkins; 2014. p. 146-151.

5. Souza AP, Kobayashi TY, LOURENCO NETO N, SILVA SMB, MACHADO MAAM, Oliveira TM. Dental manifestations of patient with vitamin D-resistant rickets. J Appl Oral Sci 2013;21:601-606. doi: 10.1590/1679775720130249.
6. Rabbani A, Rahmani P, Ziaee V, Ghodoosi S. Dental problems in hypophosphatemic rickets, a cross sectional study. Iran J Pediatr Dec 2012;22:531-534.

7. Koch G, Poulsen S, Espelid I, Haubek D. Pediatric dentistry: a clinical approach. 2nd ed. Seoul: Koonja; 2011. p. 284-295.

8. Batra P, Tejani Z, Mars M. X-linked hypophosphatemia: dental and histologic findings. J Can Dent Assoc 2006; 72:69-72.

9. Souza MA, Soares Junior LA, Santos MA, Vaisbich MH. Dental abnormalities and oral health in patients with Hypophosphatemic rickets. Clinics (Sao Paulo) 2010;65: 1023-1026. doi: 10.1590/S1807-59322010001000017.

10. Witkop CJ Jr. Hereditary defects of dentin. Dent Clin North Am 1975;19:25-45.

11. Yamamoto T. Diagnosis of X-linked hypophosphatemic vitamin D resistant rickets. Acta Paediatr Jpn 1997;39: 499-502.

12. Seow WK, Romaniuk K, Sclavos S. Micromorphologic features of dentin in vitamin D-resistant rickets: correlation with clinical grading of severity. Pediatr Dent 1989; 11:203-208.

13. Carpenter TO. New perspectives on the biology and treatment of X-linked hypophosphatemic rickets. Pediatr Clin North Am 1997;44:443-466. doi: 10.1016/S00313955(05)70485-5.

14. Park YH, Choi BJ, Lee JG. Hypophosphatemic rickets: Case Report. J Korean Acad Pediatr Dent 2000;27:108112.

15. Lee SJ, Kim YJ, Jang KT, Lee SH, Kim CC, Hahn SH, Kim JW. X-linked hypophosphatemic rickets: Case Report. J Korean Acad Pediatr Dent 2009;36:298-304. 